\title{
ANALISIS KINERJA KEUANGAN GBI BETHANY DEPOK SEBELUM DAN SESUDAH PENERAPAN PSAK NO.45
}

\author{
Mishelei Loen \\ Fakultas Ekonomi Universitas Krisnadwipayana \\ Jalan Unkris Jatiwaringin Jakarta Timur \\ e-mail: mishelei.loen@gmail.com
}

\begin{abstract}
In this study the object of a non-profit organization focuses on Depok Bethany Church, located on Jalan Mawar 8 B Depok, Pancoranmas, Depok, West Java. In research conducted at this church uses descriptive qualitative data analysis techniques. The results of the study found that the GBI Bethany Depok financial statements in the form of simple recording in cash diaries, which are then transferred to monthly reports in the form of receipts and expenses recorded when the transaction occurred. GBI Bethany Depok financial performance is not in accordance with Statement of Financial Accounting Standards (PSAK) No.45
\end{abstract}

Keywords:Financial Performance, Financial Statements, Statement of Financial Accounting Standards (PSAK) No.45

\section{PENDAHULUAN}

Dalam setiap kegiatan organisasi nirlaba maupun laba, tidak terpisah dari aktivitas pelaporan keuangan, baik hanya untuk suatu pertanggung jawaban, maupun digunakan dalam mengambil suatu keputusan. Laporan keuangan pada organisasi nirlaba dapat digunakan untuk menambah kepercayaan setiap donatur dalam mendonasikan dana kepada organsasi nirlaba tersebut. Organisasi nirlaba menurut Gultom dan Poputra (2015:10) adalah bagian dari organisasi nirlaba yang sangat berperan penting dalam membangun Iman Percaya bagi setiap jemaatnya adalah gereja.

Sedangkan Hendrawan (2015:25) menyatakan bahwa organisasi nirlaba, termasuk gereja, memperoleh dan ada dari sumbangan setiap jemaat dan tanpa menuntut suatu imbalan atau pamrih.

Organisasi nirlaba adalah suatu organisasi yang bersasaran pokok untuk mendukung suatu isu atau perihal di dalam menarik perhatian publik untuk suatu tujuan komersil, tanpa ada perhatian terhadap hal-hal yang bersifat mencari laba (moneter).

$$
\text { Seiring berkembangnya }
$$
zaman menyebabkan semakin tersturkturnya suatu pengelolaan badan usaha atau perusahaan. Semakin banyaknya peningkatan aktivitas suatu badan usaha atau perusahaan dirasakan sebagai beban yang berat. Oleh karena itu agar supaya kegiatan usaha dapat berjalan dengan baik, maka perusahaan membutuhkan suatu informasi mengenai perusahaan tersebut dengan baik, benar, serta akurat juga 
dapat diandalkan melalui laporan keuangannya.

Pelaporan keuangan organisasi nirlaba diatur dalam Pernyataan Standar Akuntansi Keuangan (PSAK) No.45 (2018:1) berisi pedoman dalam menyajikan suatu laporan keuangan organisasi nirlaba supaya relevan, andal, mudah untuk dipahami, dan mempunyai daya banding yang tinggi. Laporan keuangan organisasi nirlaba terdiri dari laporan posisi keuangan, laporan aktivitas, laporan arus kas, dan catatan atas laporan keuangan Ikatan Akuntan Indonesia (2018:1). Laporan keuangan merupakan produk utama dari akuntansi yang mampu menggambarkan kinerja dari organisasi-organisasi tersebut. Secara umum, tujuan laporan keuangan adalah untuk memberikan informasi tentang posisi keuangan, kinerja, dan arus kas perusahaan yang bermanfaat bagi sebagian besar kalangan pengguna laporan dalam rangka membuat keputusan-keputusan ekonomi serta menunjukkan pertanggungjawaban manajemen atas pengunaan sumber-sumber daya yang dipercayakan kepada mereka. Laporan keuangan setidaknya disajikan secara tahunan dan harus menyajikan secara wajar posisi keuangan, kinerja keuangan, perubahan ekuitas, dan arus kas.

Gereja Bethany Depok yang berlokasi di jalan Mawar 8 B Depok, Pancoranmas, Depok, Jawa Barat menerima pendanaan maupun pendapatan yang bersumber dari sumbangan jemaat, berupa persembahan Diakonia, Misi, persembahan ibadah minggu, dan persembahan ibadah komisi. Dalam hal ini jemaat tidak mengharapkan suatu imbalan. Pelaporan atas transaksi tersebut diatur dalam Pernyataan Standar Akuntansi Keuangan (PSAK) No.45. Laporan keuangan Gereja Bethany Depok hanya berupa laporan kas yang disebut dengan pencatatan kas, bertujuan melaporkan saldo kas di bank dan di bendahara periode mingguan dan direkap dalam bulanan. Sistem pencatatan dan pelaporan keuangan tersebut tidak dipermasalahkan oleh jemaat sebagai pemberi sumbangan, namun ada kalanya terjadi perbedaan jumlah sumbangan yang dicatat dalam tanda terima penyerahan sumbangan dengan yang diumumkan dalam laporan mingguan kepada jemaat. Oleh karena itu gereja sebagai organisasi yang perlu mempertanggung jawabkan semua sumbangan dari jemaat, agar lebih jelas dan terperinci dalam melaporkan keuangannya. Disamping itu laporan keuangan tersebut dapat digunakan untuk menilai kinerja organisasi yaitu gereja. Berdasarkan latar belakang diatas tujuan penelitian yang ingin dicapai pada penelitian ini adalah
1. Menganalisis penerapan Pernyataan Standar Akuntansi Keuangan (PSAK) No.45 di dalam pelaporan keuangan Gereja

2. Menganalisis kinerja keuangan gereja sebelum dan sesudah penerapan PSAK No.45 


\section{LANDASAN TEORI}

\section{Pengertian organisasi nirlaba}

Organisasi adalah peran sistem, aliran aktivitas dan proses relasi kerja dan melibatkan beberapa orang sebagai pelaksana tugas yang didisain untuk mencapai tujuan bersama, Torang (2015:25). Nirlaba adalah istilah dari sesuatu yang bertujuan sosial, kemasyarakatan atau lingkungan yang tidak sematamata untuk mencari keuntungan materi, Tinungki (2014:25).

Organisasi Nirlaba adalah suatu organisasi yang tujuannya tidak untuk hal komersil dan bersifat melayani masyarakat, diantaranya sekolah negeri, derma publik, rumah sakit, klinik publik, organisasi politis, bantuan masyarakat dalam hal perundang-undangan, organisasi jasa sukarelawan, serikat buruh, asosiasi profesional, institut riset, museum, dan beberapa para petugas pemerintah serta gereja, Pontoh (2014:131).

\section{Gereja}

Menurut buku yang dibuat oleh tata lokal gereja Sinode GKIN (1980), gereja berasal dari bahasa portugis "Igreya" kemudian masuk ke Indonesia, berubah menjadi "Gereja". Sedangkan bahasa Yunaninya adalah "Kyriske" yang artinya "milik Tuhan", yaitu mereka yang percaya kepada Yesus. Dan ada lagi istilah yang lain yaitu "Ekklesia" yang berarti persekutuan dari orangorang yang dipanggil keluar dari kegelapan kepada terang-Nya yang ajaib (1Petrus 2:9).

Menurut Peraturan Bersama Mentri Agama Dan Menteri Dalam Negeri (Nomor 9 Tahun 2006 dan Nomor : 8 Tahun 2006) rumah ibadat adalah Bangunan yang memiliki ciriciri tertentu yang khusus dipergunakan untuk beribadah bagi para pemeluk masing-masing agama secara permanen, tidak termasuk tempat ibadah keluarga.

\section{Perbedaan Sektor Bisnis, Sektor Pemerintah, dan Sektor Sosial}

Tabel 1. Perbedaan sektor bisnis, sektor pemerintah, dan sektor sosial

\begin{tabular}{|c|c|c|c|}
\hline $\begin{array}{l}\text { Aspek } \\
\text { Perbedaan }\end{array}$ & $\begin{array}{l}\text { Sektor } \\
\text { Bisnis }\end{array}$ & $\begin{array}{l}\text { Sektor } \\
\text { Publik } \\
\text { (pemerin } \\
\text { tah) }\end{array}$ & $\begin{array}{l}\text { Sektor } \\
\text { Sosial }\end{array}$ \\
\hline $\begin{array}{l}\text { Tujuan } \\
\text { Organisasi }\end{array}$ & $\begin{array}{l}\text { - } \\
\text { Lencari } \\
\text { (Profit } \\
\text { oriented } \\
\text { ) } \\
\text { - } \\
\text { Penyedi } \\
\text { aan } \\
\text { barang } \\
\text { dan jasa } \\
\text { komersi } \\
\text { al }\end{array}$ & $\begin{array}{l}- \\
\text { Nonprofi } \\
t \\
- \\
\text { Pelayana } \\
\mathrm{n} \text { publik } \\
\text { (public } \\
\text { service } \\
\text { oriented) }\end{array}$ & $\begin{array}{l}\text { - } \\
\text { fit } \\
- \\
\text { Pelayan } \\
\text { an } \\
\text { sosisal } \\
\text { dan } \\
\text { kemanu } \\
\text { siaan } \\
\text { (social } \\
\text { \&huma } \\
\text { nity } \\
\text { service) }\end{array}$ \\
\hline $\begin{array}{l}\text { Sumber } \\
\text { Pendanaan }\end{array}$ & $\begin{array}{l}\text { storan } \\
\text { modal, } \\
\text { laba } \\
\text { ditahan, } \\
\text { hasil } \\
\text { penjuala } \\
\text { n, } \\
\text { utang, } \\
\text { penerbit } \\
\text { an } \\
\text { saham }\end{array}$ & $\begin{array}{l}\text { Pajak, } \\
\text { PNBP, } \\
\text { retribusi, } \\
\text { utang, } \\
\text { bagian } \\
\text { laba } \\
\text { perusaha } \\
\text { an } \\
\text { negara, } \\
\text { hibah, } \\
\text { penjualan } \\
\text { aset }\end{array}$ & $\begin{array}{l}\text { Donasi, } \\
\text { pendap } \\
\text { atan } \\
\text { hasil } \\
\text { usaha, } \\
\text { utang }\end{array}$ \\
\hline Kepemilikan & $\begin{array}{l}\text { Dimiliki } \\
\text { pemega } \\
\text { ng } \\
\text { saham } \\
\text { (stakeho }\end{array}$ & $\begin{array}{l}\text { Dimiliki } \\
\text { negara } \\
\text { atau } \\
\text { seluruh } \\
\text { rakyat }\end{array}$ & $\begin{array}{l}\text { Dimilik } \\
\text { i oleh } \\
\text { masyar } \\
\text { akat }\end{array}$ \\
\hline
\end{tabular}

Copyright (c) 2020 Mishelei Loen, SE., M.Si. 


\begin{tabular}{|c|c|c|c|}
\hline & lder) & & \\
\hline $\begin{array}{l}\text { Pertanggungj } \\
\text { awaban }\end{array}$ & $\begin{array}{l}\text { Kepada } \\
\text { pemega } \\
\text { ng } \\
\text { saham } \\
\text { dan } \\
\text { investor }\end{array}$ & $\begin{array}{l}\text { Kepada } \\
\text { rakyat } \\
\text { dan } \\
\text { parlemen } \\
\text { (DPR/DP } \\
\text { RD) }\end{array}$ & $\begin{array}{l}\text { Kepada } \\
\text { masyar } \\
\text { akat } \\
\text { dan } \\
\text { pemberi } \\
\text { dana }\end{array}$ \\
\hline $\begin{array}{l}\text { Struktur } \\
\text { Organisasi }\end{array}$ & $\begin{array}{l}\text { Struktur } \\
\text { Organis } \\
\text { asi } \\
\text { Bisnis }\end{array}$ & $\begin{array}{l}\text { Struktur } \\
\text { birokrasi } \\
\text { (pemerint } \\
\text { ahan) }\end{array}$ & $\begin{array}{l}\text { Struktur } \\
\text { organis } \\
\text { asi } \\
\text { sosial }\end{array}$ \\
\hline $\begin{array}{l}\text { Karakteristik } \\
\text { Anggaran }\end{array}$ & $\begin{array}{l}- \\
\text { Tertutu } \\
\mathrm{p} \text { untuk } \\
\text { publik } \\
- \\
\text { Merupa } \\
\text { kan } \\
\text { dokume } \\
\mathrm{n} \\
\text { rahasia } \\
\text { (confide } \\
\text { ntal) }\end{array}$ & $\begin{array}{l}\text {-Terbuka } \\
\text { untuk } \\
\text { publik } \\
\text { - } \\
\text { Merupak } \\
\text { an } \\
\text { dokumen } \\
\text { publik }\end{array}$ & $\begin{array}{l}- \\
\text { Terbuk } \\
\text { a untuk } \\
\text { publik }\end{array}$ \\
\hline $\begin{array}{l}\text { Sistem } \\
\text { Akuntansi }\end{array}$ & $\begin{array}{l}\text { Acrual } \\
\text { Account } \\
\text { ing }\end{array}$ & $\begin{array}{l}\text {-Cash } \\
\text { accounti } \\
n g \\
\text {-Accrual } \\
\text { Accounti } \\
n g \\
- \text { Fund } \\
\text { Accounti } \\
n g \\
- \\
\text { Budgetar } \\
y \\
\text { accounti } \\
\text { ng } \\
- \\
\text { Commit } \\
\text { ment } \\
\text { accounti } \\
\text { ng }\end{array}$ & $\begin{array}{l}\text {-Cach } \\
\text { account } \\
\text { ing } \\
- \\
\text { Accrual } \\
\text { Account } \\
\text { ing } \\
\text {-Fund } \\
\text { Account } \\
\text { ing } \\
- \\
\text { Budget } \\
\text { ary } \\
\text { account } \\
\text { ing }\end{array}$ \\
\hline $\begin{array}{l}\text { Standar } \\
\text { Akuntansi }\end{array}$ & $\begin{array}{l}\text { Standar } \\
\text { akuntan } \\
\text { si bisnis } \\
\text { (Standar } \\
\text { Akunta } \\
\text { nsi } \\
\text { Keuang } \\
\text { an) }\end{array}$ & $\begin{array}{l}\text { Standar } \\
\text { Akuntans } \\
\text { i } \\
\text { Pemerint } \\
\text { ahan }\end{array}$ & $\begin{array}{l}\text { Standar } \\
\text { Akunta } \\
\text { nsi } \\
\text { Organis } \\
\text { asi } \\
\text { Nirlaba }\end{array}$ \\
\hline
\end{tabular}

Sumber (Mahmudi : 2016)

\section{Akuntansi Organisasi Nirlaba berdasarkan Pernyataan Standar Akuntansi Keuangan (PSAK) No.45}

Tujuan dari Pernyataan Standar Akuntansi Keuangan (PSAK) No.45(revisi 2018), mengatur pelaporan keuangan entitas nirlaba. Dengan adanya pedoman pelaporan diharapkan pelaporan keuangan entitas nirlaba dapat lebih mudah dipahami, memiliki relevansi, dan memiliki daya banding yang tinggi. Laporan keuangan untuk entitas nirlaba terdiri dari laporan posisi keuangan, laporan aktivitas, laporan arus kas, dan catatan atas laporan keuangan. Laporan tersebut berbeda dengan laporan keuangan untuk entitas bisnis pada umumnya.

\section{Ruang Lingkup Entitas Nirlaba}

Menurut Pernyataan Standar Akuntansi Keuangan (PSAK) No.45 (revisi 2018) ruang lingkup yang termsuk dalam pangakuan entitas nirlaba dinyatakan dalam beberapa pernyataan sebagai berikut:

1. Apabila sumber daya entitas nirlaba berasal dari pemberi sumber daya yang tidak mengharapkan imbalan.

2. Menghasilkan barang/jasa yang tidak bertujuan untuk mencari keuntungan, dan jikalau mendapatkan keuntungan tidak dibagikan kepada pemilik entitas nirlaba.

3. Tidak adanya kepemilikan seperti halnya entitas bisnis, dalam artian tidak diperjual belikan, dialihkan, serta ditebus kembali.

\section{Pengukuran Entitas Nirlaba}

Copyright (c) 2020 Mishelei Loen, SE., M.Si

This work is licensed under a Creative Commons Attribution-NonCommercial-ShareAlike 4.0 Internationa 
Menurut Pernyataan Standar Akuntansi (PSAK) No.45 (2018:2) yang menjadi dasar pengukuran dalam setiap entitas nirlaba yaitu sebagai berikut:

1. Pembatasan pemanen adalah pembatasan penggunaan sumber daya yang ditetapkan oleh pemberi sumber daya yang tidak mengharapkan pembayaran kembali agar sumber daya tersebut dipertahankan secara permanen, tetapi entitas nirlaba diizinkan untuk menggunakan sebagian atau semua penghasilan dan manfaat ekonomi lain yang berasal sumber daya tersebut.

2. Pembatasan temporer adalah pembatasan penggunaan sumber daya oleh pemberi sumber daya yang tidak mengharapkan pembayaran kembali yang menetapkan agar sumber daya tersebut dipertahankan sampai dengan periode tertentu atau sampai dengan terpenuhinya keadaan tertentu.

3. Sumber daya terikat adalah sumber daya yang penggunaanya dibatasi untuk tujuan tertentu oleh pemberi sumber daya yang tidak mengharapkan pembayaran kembali. Pembatasan tersebut dapat bersifat permanen atau temporer.

4. Sumber daya tidak terikat adalah sumber daya yang penggunaanya tidak dibatasi untuk tujuan tertentu oleh pemberi sumber daya yang tidak mengharapkan pembayaran kembali.

\section{Unsur-unsur Laporan Keuangan Entitas Nirlaba}

Pernyataan Standar Akuntansi (PSAK) No.45 (revisi 2018), laporan keuangan entitas nirlaba meliputi komponen-komponen berikut ini:

\section{a. Laporan Posisi Keuangan}

Tujuan laporan posisi keuangan adalah untuk menyediakan informasi mengenai aset, liabilitas, dan aset neto serta infomasi mengenai hubungan di antara unsur-unsur tersebut pada waktu tertentu. Laporan posisi keuangan mencakup entitas nirlaba secara keseluruhan dan menyajikan total aset, liabilitas, dan aset neto. Laporan posisi keuangan, termasuk catatan atas laporan keuangan, menyediakan infornasi yang relevan mengenai likuiditas, fleksibel keuangan, dan hubungan antara aset dan liabilitas.

b. Laporan Aktivitas

Tujuan utama laporan aktivitas adalah menyediakan informasi mengenai pengaruh transaksi dan peristiwa lain yang mengubah jumlah dan sifat neto ; hubungan antar transaksi dan peristiwa lain;dan bagaimana penggunaan sumber daya dan pelaksanan berbagai program dan jasa.laporan aktivitas mencakup entitas nirlaba secara keseluruhan dan menyajikan perubahan jumlah 
aset neto selama satu periode, menyajikan jumlah perubahan aset neto terikat permanen, terikat temporer, dan tidak terikat dalam satu periode, pendapatan sebagai penambah aset neto tidak terikat kecuali pengunaanya di batasi oleh pemberi sumber daya yang tidak mengharapkan pembayaran kembali, dan menyajikan beban sebagai pengurang aset neto tidak terikat.

c. Laporan Arus Kas

Tujuan utama laporan arus kas adalah menyajikan informasi mengenai penerimaan dan pengeluaran kas dalam suatu periode.

Penyajian laporan arus kas harus digolongkan kedalam tiga kategori yaitu:

1. Aktivitas operasi

2. Aktivitas investasi, dan

3. Aktivitas pendanaan

d. Catatan Atas Laporan Keuangan

Catatan atas laporan keuangan merupakan bagian yang tidak bisa terpisah dari laporan-laporan diatas. Tujuan pemberian catatan ini agar seluruh informasi keuangan yang dianggap perlu untuk diketahui pembacanya sudah diungkapkan.

METODE PENELITIAN
Dalam penelitian ini memfokuskan objek organisasi nirlaba pada Gereja Bethany Depok yang berlokasi di jalan Mawar 8 B Depok, Pancoranmas, Depok, Jawa Barat. Dalam Penelitian yang dilakukan di Gereja ini menggunakan teknik analisis data Deskriptif Kualitatif

\section{HASIL PENELITIAN DAN PEMBAHASAN}

\section{Gambaran Umum Gereja Bethany}

GBI Bethany Depok (sekarang GBI Kamboja) memulai ibadah perdana di Kota Depok dengan menyewa ruangan di Hotel Bumi Wiyata, Jalan Margonda Raya, dengan jumlah jemaat mula-mula 116 orang. GBI Kamboja di bawah penggembalaan Pdp Ir Jongky $T$ Widjojo merupakan ranting pertama dari GBI Sawangan. Jemaat GBI Kamboja terus bertambah dan berkembang ke seluruh kota Depok, sehingga dibuka lagi ranting-ranting baru di Depok Timur, BillabongBojonggede, Mekarsari, Simpangan Depok, Rajabrana, Lenteng Agung, dan Pasar Minggu. Pada 4 Juli 2005, pembangunan gedung gereja di Jalan Kamboja No 18 telah selesai dan diresmikan. Sesuai Tata Gereja GBI, nama gereja ini menjadi GBI Jalan Kamboja No 18 Depok. Pada tahun 2006, Gembala Pembina Pdt Dr Ir Niko Njotorahardjo mengangkat Pdt Jongky Gembala Rayon 9, menggantikan Pdt. Soewito Njotorahardjo yang meninggal dunia pada 13 Februari 2006. Secara

Copyright (c) 2020 Mishelei Loen, SE., M.Si

This work is licensed under a Creative Commons Attribution-NonCommercial-ShareAlike 4.0 International License. 
efektif, GBI Kamboja juga menjadi jemaat induk bagi GBI Rayon 9 di bawah pembinaan GBI Jalan Gatot

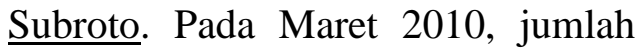
jemaat telah mencapai lebih dari 2500 jemaat dewasa dan 450 anakanak

\section{Hasil Penelitian \\ Kebijakan Pengelolaan Keuangan Gereja Bethany}

GBI Bethany yang pada dasarnya merupakan sarana pembangunan iman percaya bagi setiap jemaat yang merindukan cinta kasih Tuhan yang didalamnya terdapat pelayan-pelayan yang melayani jemaat. Gereja memperoleh dukungan sumbangan dana berasal dari jemaat yang memberikan donatur untuk pembangunan gereja dan mendukung segala kegiatan gereja, kemudian dikelola dengan baik tanpa adanya penyalahgunaan. Segala pelayanan keuangan gereja pada dasarnya merupakan pelayanan kepada jemaat sekaligus pertanggungjawaban dari setiap dana yang masuk kedalam Kas dengan pencatatan keuangan yang baik.

Berdasarkan observasi yang dilakukan peneliti pada GBI Bethany pada administrasi yang dikelola oleh majelis dibidang bendahara merupakan hasil dari pemanfaatan kas yang diperoleh dari setiap persembahan ibadah raya, maupun ibadah persekutuan.

\section{Penerimaan Keuangan GBI Bethany}

Sumber dana yang dikelola
oleh GBI Bethany Bethania
bersumber dari persembahan
kegiatan ibadah hari minggu yang
dilaksanakan pada jam 09:00 pagi
sampai jam 11:00 siang. Pendapatan
yang berupa persembahan,
penerimaan lain-lain, dan sumbangan. Di dalam persembahan bersumber dana yang berasal dari persembahan ibadah raya maupun ibadah persekutuan, di dalam penerimaan lain-lain terdapat dana yang berasal dari persembahan persepuluhan, dan pengembalian kelebihan dana dari komisi, di dalam sumbangan terdapat dana yang bersasal dari sumbangan jemaat, persembahan misi dan penginjilan, maupun dana pembangunan gedung.

Setiap dana persembahan yang terkumpul seperti amplop ataupun tanpa amplop langsung dihitung sehabis ibadah persekutuan selesai dilaksanakan yang kemudian dicatat didalam buku harian kas yang kemudian diumumkan pada minggu selanjutnya sehabis ibadah persekutuan selesai dilaksanakan atau pada saat warta jemaat diumumkan. Semua Dana yang diperoleh di dalam kas kecil akan di setorkan ke kas di bank pada akhir bulan, tetapi ada saldo yang ditentukan mengendap pada kas kecil yaitu senilai Rp.600.000 .

\section{Pengeluaran Keuangan GBI Bethany}

Pengeluaran yang dilakukan oleh gereja berdasarkan dari kas yang diterima dari persembahan umum, persepuluhan, sumbangan 
khusus, pembangunan gereja yaitu seperti pengeluaran untuk konsumsi, foto copy berkas dokumen, bayar listrik, air ,dan telepon, transportasi, diakonia, tunjangan, komisi, misi penginjilan, TAP 5\%, Sinode.

Semua pengeluaran diatur oleh gereja berdasarkan dari setiap peruntukan uang itu ditempatkan dan semua itu selalu dicatat didalam buku kas sebagai catatan agenda kerja dari setiap majelis yang bertugas di gereja.

\section{Anggaran Keuangan dan Laporan Realisasi Anggaran GBI Bethany}

Kegiatan akuntansi yang dilaksanakan di dalam GBI Bethany semuanya didasarkan dari penyusunan anggaran yang kemudian menjadi acuan dalam terlaksananya setiap program supaya tidak terjadinya kekurangan dana melainkan yang diharapkannya selain tercukupinya dana dan ada kelebihan dari setiap dana untuk lebih di gunakan lagi guna pengembangan jemaat.

Anggaran keuangan gereja disusun oleh semua pelayan majelis yang kemudian dibahas didalam rapat kerja untuk kegiatan yang akan dilaksanakan dalam satu tahun kedepan, segala kegiatan yang dilaksanakan semuanya didasarkan kepada anggaran keuangan, dan apabila terjadinya kekurangan dana untuk melakukan program maka, program yang akan dilaksanakan harus di tunda atau dibatalkan, atau mencari sumber dana lain melalui strategi pencarian dana.

\section{Pembahasan}

\section{Laporan Keuangan \\ Laporan Keuangan GBI Bethany Depok}

Laporan posisi keuangan adalah akun yang terjadi akibat adanya suatu program yang terdapat di GBI Bethany Depok yang menyebabkan pendapatan dana pada GBI Bethany Depok seperti pendapatan persembahan, penerimaan lain-lain, dan sumbangan. Kemudian akan digunakan untuk setiap kegiatan program serta operasional guna membangun iman percaya setiap jemaat.

Tabel 2. Laporan posisi keuangan semester 1 dan semester 2 tahun 2019

\begin{tabular}{|c|c|c|c|c|}
\hline Aset & & mester 1 & & emester 2 \\
\hline Kas dan Setara Kas & $\mathrm{Rp}$ & 97.582 .794 & $\mathrm{Rp}$ & 78.765 .559 \\
\hline Perlengkapan & $\mathrm{Rp}$ & 2.181 .077 & $\mathrm{Rp}$ & 2.681 .077 \\
\hline Tanah & $\mathrm{Rp}$ & 527.000 .000 & $\mathrm{Rp}$ & 527.000 .000 \\
\hline Bangunan & $\mathrm{Rp}$ & 446.250 .000 & $\mathrm{Rp}$ & 446.250 .000 \\
\hline Akumulasi Penyusutan Bangunan & $\mathrm{Rp}$ & $(11.156 .250)$ & $\mathrm{Rp}$ & $(11.156 .250$ \\
\hline Peralatan & $\mathrm{Rp}$ & 217.396 .500 & $\mathrm{Rp}$ & 217.396 .500 \\
\hline Akumulasi Penyusutan Peralatan & $\mathrm{Rp}$ & $(25.672 .313)$ & $\mathrm{Rp}$ & $(25.672 .312$ \\
\hline Total Aset & $\mathrm{Rp}$ & 1.253.581.808 & $\mathrm{Rp}$ & 1.235 .264 .574 \\
\hline Liabilitas dan Aset Neto & & - & & - \\
\hline Liabilitas & & - & & - \\
\hline Jumlah Liabilitas & & - & & - \\
\hline Aset Neto & & & & \\
\hline Tidak Terikat (Catatan B) & $\mathrm{Rp}$ & 13.044 .742 & $\mathrm{Rp}$ & 9.223 .704 \\
\hline Terikat Temporer (Catatan C) & $\mathrm{Rp}$ & 49.890 .566 & $\mathrm{Rp}$ & 35.394 .370 \\
\hline Terikat Permanen (Catatan D) & $\mathrm{Rp}$ & 1.190 .646 .500 & $\mathrm{Rp}$ & 1.190 .646 .500 \\
\hline Total Liabilitas dan Aset Neto & $\mathrm{Rp}$ & 1.253 .581 .808 & $\mathrm{Rp}$ & 1.235 .264 .574 \\
\hline
\end{tabular}

Kas dan Setara Kas.

Berasal dari saldo akhir dari buku besar kas kecil dan bank yang kemudian di jumlah dan di sajikan pada tabel di atas.

Perlengkapan.

Berasal dari saldo akhir buku besar di bagian akun perlengkapan 
yang berisi saldo perlengkapan maupun dana yang dipergunakan untuk perlengkapan disajikan pada tabel di atas.

Tanah.

Berasal dari saldo akhir buku besar di bagian akun tanah dan disajikan pada tabel di atas.

Bangunan.

Berasal dari saldo akhir buku besar di bagian akun bangunan dan disajikan pada tabel di atas.

Akumulasi Penyusutan Bangunan.

Berasal dari saldo akhir buku besar di bagian akun akumulasi penyusutan bangunan dan disajikan pada tabel di atas.

Peralatan.

Berasal dari saldo akhir buku besar di bagian akun peralatan dan disajikan pada tabel di atas.

Akumulasi Penyusutan Peralatan.

Berasal dari saldo akhir buku besar di bagian akun akumulasi penyusutan peralatan dan disajikan pada tabel di atas.

Total Aset.

Berasal dari seluruh jumlah aset yaitu aset lancar yang berisi kas dan setara kas, perlengkapan, aset tetap yang berisi peralatan, akumulasi penyusutan peralatan, tanah, bangunan,dan akumulasi penyusutan bangunan kemudian disajikan pada tabel di atas.

Liabilitas.

GBI Bethany Depok tidak mempunyai liabilitas maka tidak disajikan nominal saldo pada tabel di atas.

Aset Neto Tidak Terikat.

Berasal dari saldo

persembahan, penerimaan lain-lain yang kemudian dikurangi beban- beban yang terinci dalam catatan $\mathrm{B}$ disajikan pada tabel di atas.

Aset Neto Terikat Temporer.

Berasal dari saldo Sumbangan yang kemudian dikurangi bebanbeban yang terinci dalam catatan $\mathrm{C}$ disajikan pada tabel di atas.

Aset Neto Terikat Permanen.

Berasal dari saldo Sumbangan peralatan, tanah, dan gedung yang terinci dalam catatan $\mathrm{D}$ disajikan pada tabel di atas.

\section{Laporan Aktivitas GBI Bethany Depok}

Laporan aktivitas memuat segala aset neto dari setiap aktivitas program baik itu tidak terikat, terikat temporer, dan terikat permanen semuanya berasal dari jemaat yang memberikan sumbangan dana yang tidak mengharapkan imbalan kembali.

Tabel 3. Laporan aktivitas semester 1 tahun 2019

\begin{tabular}{|c|c|c|c|c|c|c|c|}
\hline \multirow{2}{*}{\begin{tabular}{|l|} 
Laporan nktivititas \\
Aset Netio
\end{tabular}} & \multicolumn{2}{|c|}{ Tidak Terikat } & \multicolumn{2}{|c|}{ Terikat Temporer } & Terikat Permanen & \multicolumn{2}{|r|}{ Jumlah } \\
\hline & Rp & 64332224 & & & & $\mathrm{Rp}$ & 64.332224 \\
\hline Persembahan (Catatan B) & Rp & 51.859 .100 & & & & Rp & 51.599 .100 \\
\hline Penrerimaan Laim-ain (Catatan B) & Rp & 142003335 & & & & Rp & 142.03 .335 \\
\hline Sumbangan (CaratanC) & & & $\mathrm{Rp}$ & 76.255 .000 & & $\mathrm{Rp}$ & 76.25 .5000 \\
\hline Sumbangan Peralatan (Catatan E) & & & & & $217,396.500$ & Rp & 217.396 .500 \\
\hline Sumbangan Tanah (Catatan D) & & & & & 527.000 .000 & $\mathrm{Rp}$ & 527.00 .000 \\
\hline Sumbangan Bangunan (CatatanD) & & & & & 46.201000 & $\mathrm{Rp}$ & 46.20 .000 \\
\hline Jumlah Pendapatan & $\mathrm{Rp}$ & 258.194 .659 & Rp & 76.255 .000 & \begin{tabular}{|ll}
0 & 1.190 .646 .500 \\
\end{tabular} & $\mathrm{Rp}$ & 1.525 .136 .150 \\
\hline \multicolumn{8}{|l|}{ Beban } \\
\hline Provgram B & Rp & 25.149 .917 & & & & Rp & 245.149 .917 \\
\hline ProvgramC & & & Rp & 26.404 .434 & & $\mathrm{Rp}$ & $26.44,434$ \\
\hline \begin{tabular}{|l|}
$J$ Jumlah Beban \\
\end{tabular} & $\mathrm{Rp}$ & 245.149 .917 & $\mathrm{Rp}$ & $26.404,434$ & & $\mathrm{Rp}$ & $271.54,51.51$ \\
\hline Aset Neto & Rp & 13.04 .742 & Rp & 49.990 .566 & \begin{tabular}{|ll}
$\operatorname{Rp}$ & 1.1900 .646 .500
\end{tabular} & $\begin{array}{ll}0 \mathrm{Rp} \\
\mathrm{RP}\end{array}$ & 1.2535858 .908 \\
\hline
\end{tabular}

Tabel 4. Laporan aktivitas semester 2 tahun 2019 


\begin{tabular}{|c|c|c|c|c|c|}
\hline Lapponan Athinitita & & & Tenkikat Tempover 1 & Tenikat Pemananen & Jumalah \\
\hline Aetelleto & Rp & $99.76+2.291$ & & & $9.76+2.291$ \\
\hline Persembahan (Catatian B) & $\mathrm{Rp}$ & 55.462000 & & & 45,462000 \\
\hline 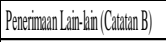 & $\mathrm{Rp}$ & 199609652 & & & $\begin{array}{ll}\operatorname{Rpp} & 1096969.52 \\
\end{array}$ \\
\hline Simlangan (Catatan C) & & & 70.262000 & & 70.62000 \\
\hline Sumbangan Peralatan (Catatan E) & & & & $\operatorname{Rp} \quad 27,396.50$ & 217,396500 \\
\hline Sumbangan Tanh (CatatanD) & & & & \begin{tabular}{ll|}
$\operatorname{Rp}$ & $527,000: 000$ \\
\end{tabular} & $57,000.000$ \\
\hline 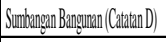 & & & & 46.20 .00001 & $46,250.000$ \\
\hline JumlahPendepplan & $\mathrm{Rp}$ & $244595,843]$ R & $70.262000 \mathrm{fr}$ & 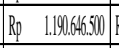 & 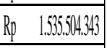 \\
\hline Belan & & & & & \\
\hline ProgamA & $\mathrm{Rp}$ & 2663521.199 & & & Rp $\quad 266352139$ \\
\hline Program B & & & 34.867 .60 & & $\begin{array}{ll}\text { Rp } & 34.466 .600 \\
\end{array}$ \\
\hline Jumlah Betan & $\mathrm{Rp}$ & $2663321.1991 \mathrm{R}$ & 34.867 .620 & & 30.29976 \\
\hline Aset Neto & $\mathrm{Rp}$ & $9.233 .74+1 \mathrm{R}$ & $35,5493010 \mathrm{R}$ & $\operatorname{Rp} \quad 1.190 .646 .5001$ & $\begin{array}{ll}\operatorname{Rpp} & 1.256 .66 .574 \\
\end{array}$ \\
\hline
\end{tabular}

\section{Laporan Arus Kas GBI Bethany Depok}

Laporan Arus Kas menyajikan laporan keuangan mengenai aktivitas masing-masing apakah itu aktivitas operasi, investasi, maupun aktivitas pendanaan. Seperti setiap penerimaan kas dari penyumbang yang tidak mengharapkan imbalan kembali, maupun beban yang terdapat dari setiap program

Tabel 5. Laporan arus kas semester 1 tahun 2019

\begin{tabular}{|c|c|c|}
\hline \multicolumn{3}{|l|}{ Aliran Kas dari Aktivitas Operasi } \\
\hline Persembahan & $\mathrm{Rp}$ & 51.859 .100 \\
\hline Penerimaan Lain-lain & $\mathrm{Rp}$ & 142.003 .335 \\
\hline Sumbangan & $\mathrm{Rp}$ & 76.295 .000 \\
\hline Jumlah & $\mathrm{Rp}$ & 270.157 .435 \\
\hline \multicolumn{3}{|l|}{ Aliran Kas dari Investasi } \\
\hline Investasi & & - \\
\hline \multicolumn{3}{|l|}{ Jumlah } \\
\hline \multicolumn{3}{|l|}{ Aliran Kas dari Pendanaan } \\
\hline Biaya Tunjangan & $\mathrm{Rp}$ & 84.880 .521 \\
\hline Biaya Konsumsi & $\mathrm{Rp}$ & 8.794 .000 \\
\hline Biaya Transportasi & $\mathrm{Rp}$ & 7.700 .000 \\
\hline Biaya Listrik, Air, dan Telphon & $\mathrm{Rp}$ & 6.664 .000 \\
\hline Biaya Foto Copy & $\mathrm{Rp}$ & 1.055 .000 \\
\hline Biaya Komisi & $\mathrm{Rp}$ & 5.360 .000 \\
\hline Biaya Diakonia & $\mathrm{Rp}$ & 6.010 .000 \\
\hline Biaya Dana Pastori & $\mathrm{Rp}$ & 48.000 .000 \\
\hline Biaya Tunjangan Akhir Pensiun (TAP) & $\mathrm{Rp}$ & 10.197.217 \\
\hline Biaya Sinode & $\mathrm{Rp}$ & 20.394 .434 \\
\hline Biaya Adm dan Pajak Bank & $\mathrm{Rp}$ & 286.616 \\
\hline Biaya Lain-lain & $\mathrm{Rp}$ & 35.384 .000 \\
\hline Jumlah & $\mathrm{Rp}$ & 234.725 .788 \\
\hline Total & $\mathrm{Rp}$ & 35.731 .647 \\
\hline Kas dan Setara Kas Awal Semester 1 & $\mathrm{Rp}$ & 61.851 .147 \\
\hline Kenaikan Kas dan Setara Kas & $\mathrm{Rp}$ & 35.731 .647 \\
\hline Kas dan Setara Kas Akhir Semester 1 & $\mathrm{Rp}$ & 97.582 .794 \\
\hline
\end{tabular}

Copyright (c) 2020 Mishelei Loen, SE., M.Si
Tabel 6. Lapran arus kas

semester 2 tahun 2019

\begin{tabular}{|c|c|c|}
\hline \multicolumn{3}{|l|}{ Aliran Kas dari Aktivitas Operasi } \\
\hline Persembahan & $\mathrm{Rp}$ & 45.462 .000 \\
\hline Penerimaan Lain-lain & $\mathrm{Rp}$ & 129.369 .572 \\
\hline Sumbangan & $\mathrm{Rp}$ & 70.262 .000 \\
\hline Jumlah & $\mathrm{Rp}$ & 245.093 .572 \\
\hline \multicolumn{3}{|l|}{ Aliran Kas dari Investasi } \\
\hline Perlengkapan & $\mathrm{Rp}$ & 500.000 \\
\hline Jumlah & $\mathrm{Rp}$ & 500.000 \\
\hline \multicolumn{3}{|l|}{ Aliran Kas dari Pendanaan } \\
\hline Biaya Tunjangan & $\mathrm{Rp}$ & 87.569 .206 \\
\hline Biaya Konsumsi & $\mathrm{Rp}$ & 10.198 .000 \\
\hline Biaya Transportasi & $\mathrm{Rp}$ & 13.275 .000 \\
\hline Biaya Listrik, Air, dan Telphon & $\mathrm{Rp}$ & 5.588 .000 \\
\hline Biaya Foto Copy & $\mathrm{Rp}$ & 1.922 .500 \\
\hline Biaya Komisi & $\mathrm{Rp}$ & 7.331 .000 \\
\hline Biaya Diakonia & $\mathrm{Rp}$ & 13.705 .000 \\
\hline Biaya Dana Pastori & $\mathrm{Rp}$ & 48.000 .000 \\
\hline Biaya Tunjangan Akhir Pensiun (TAP) & $\mathrm{Rp}$ & 10.581 .315 \\
\hline Biaya Sinode & $\mathrm{Rp}$ & 21.162 .630 \\
\hline Biaya Renovasi & $\mathrm{Rp}$ & 14.145 .000 \\
\hline Biaya Adm dan Pajak Bank & $\mathrm{Rp}$ & 288.156 \\
\hline Biaya Lain-lain & $\mathrm{Rp}$ & 29.645 .000 \\
\hline Jumlah & $\mathrm{Rp}$ & 263.410 .807 \\
\hline Total & $\mathrm{Rp}$ & $(18.817 .235$ \\
\hline Kas dan Setara Kas Awal Semester 2 & $\mathrm{Rp}$ & 97.582 .794 \\
\hline Penurunan Kas dan Setara Kas & $\mathrm{Rp}$ & $(18.817 .235$ \\
\hline Kas dan Setara Kas Akhir Semester 2 & $\mathrm{Rp}$ & 78.765 .559 \\
\hline
\end{tabular}

\section{KESIMPULAN \\ SARAN}

\section{Kesimpulan}

Laporan keuangan GBI Bethany Depok berupa pencatatan sederhana pada buku harian kas, yang kemudian di pindahkan ke laporan bulanan yang berupa penerimaan dan pengeluaran yang di catat saat terjadinya transaksi, maka dari itu penulis mengolah data keuangan sehingga menjadi laporan keuangan yang sesuai Pernyataan Standar Akuntansi Keuangan (PSAK) No.45 yang dibagi menjadi dua semester sehingga hasilnya dapat mudah dipahami, memiliki relevansi, dan memiliki daya banding yang tinggi. Kinerja keuangan GBI

\section{(c) $(1)$ ()}

This work is licensed under a Creative Commons Attribution-NonCommercial-ShareAlike 4.0 International License. 
Bethany Depok sebelum dilakukannya penerapan Pernyataan Standar Akuntansi Keuangan (PSAK) No.45 belum dapat dianalisis.

\section{Saran}

Sebaiknya GBI Bethany Depok melakukan penataan keuangan dan akuntansi yaitu melakukan pelatihan sertifikasi Teknisi Akuntansi, supaya dapat meningkatkan pelayanan di bidang keuangan dan pelaporan keuangan yang disusun sesuai dengan Penyataan Standar Akuntansi Keuangan (PSAK) No.45, sehingga dapat mempermudah dalam melakukan analisis kinerja keuangan.

Diharapkan hasil penelitian yang dilakukan ini dapat menjadi acuan untuk menyusun laporan keuangan ditahun yang selanjutnya, dan mengukur kinerja keuangan.

\section{DAFTAR PUSTAKA}

Bastian, Indra. (2007). Akuntansi Untuk LSM Dan Partai Politik, Jakarta. Erlangga

Eiodia. (2012). Analisis Kinerja Keuangan Oraganisasi Nirlaba (Studi Kasus Pada Yayasan Sion), Skripsi: Universitas Kristen Satya Wacana Salatiga

Hendrawan, Rony. (2011). Analisis

Penerapan PSAK No. 45

Tentang

Pelaporan

Keuangan

Organisasi

Nirlaba Pada Rumah Sakit

Berstatus Badan Layanan

Umum. Skripsi. Fakultas
Ekonomi Universitas

Diponegoro. Semarang

Hermanto, Bambang. (2015). Pajak

Penghasilan Badan \& Pajak

Pertambahan Nilai dan Pajak

Penjualan Barang Mewah,

Jakarta; Lentera Ilmu

Cendekia

Hery, Cand. (2013). Teori Akuntansi,

Fakultas Ekonomi

Universitas Indonesia. Jakarta

Hery, Cand. (2014). Akuntansi

Dasar 1 dan 2. Jakarta.

Grasindo

Ikatan Akuntan Indonesia (IAI). (2018). Standar Akuntansi Keuangan Efektif per 1 Januari 2018. Jakarta. Ikatan Akuntan Indonesia

Janis, S.R, dan Budiarso, S.N. (2017). Analisis Penerapan Psak No. 45 Tentang Pelaporan Keuangan Entitas Nirlaba Pada Jemaat Gmist Pniel Biau Kab, Kep. Sitaro, Universitas Sam Ratulangi Manado, Journal Accountability 103-111 No.1. Vol 6.

J.C.Ihemeje , Geff Okereafor, Bashir M. Ogungbangbe. (2015).

The Use of Accounting System in the NonprofitOriented Church, Organizations of Nigeria College of Management Sciences, Michael Okpara University of Agriculture, Umudike..Jurnal ISSN 18495419. Volume 1, Issue 12, November 2015, Pages 58-66

Komisi Theologia Sinode GKIN. (1980). Penuntun Dasar

Copyright (c) 2020 Mishelei Loen, SE., M.Si. 
Katekisasi. Gereja Kristen Injili Nusantara

Livita. (2015). Analisis Penerapan Akuntansi Organisasi Nirlaba Entitas Gereja Berdasarkan Pernyataan Standar Akuntansi Keuangan No. 45 (Studi Kasus Gereja Masehi Injili Di Minahasa Baitel Kolongan), Skripsi; Kementerian Riset Teknologi Dan Pendidikan Tinggi Politeknik Negeri Manado Mahmudi. (2016). Akuntansi Sektor Publik, Edisi Revisi, Yogyakarta. UII Press Yogyakarta

Mamesah, Melisa. (2013). Penerapan Psak No.45 Pada Gmim Efrata Sentrum Sonder Kaitannya Dengan Kualitas Informasi Laporan Keuangan, Universitas Sam Ratulangi Manado. Jurnal EMBA ISSN 2303-1174 No.4.

Mulyadi. (2007). Sistem Terpadu Pengelolaan Kinerja Personel Berbasis Balanced Scorecard, UPP STIM YKPN; Yogyakarta

Marshall B. Romney dan Paul John Steinbart. (2017). Sistem Informasi Akuntansi, Accounting Information Systems (Edisi13) Jakarta: Salemba Empat

Oti, Peter A. Asuquo, Akabom-Ita. (2016). Framework of Church Accounting in Nigeria: Pragmatic Examination of the Problems, Prospects and Financial Implications of Proliferation of Churches, Department of
Accounting, Faculty of Management Sciences, University of Calabar, Jurnal ISSN 2422-

8451.JournalVol.27,2016.http s://iiste.org/Journals/index.ph p/JMCR/article/download/33 114/34013. Diakses Februari,7,2019. Hal 1-15

Pontoh, Chenly. (2013). Penerapan Laporan Keuangan Organisasi Nirlaba Berdasarkan Psak No 45 Pada Gereja Bzl, Universitas Sam Ratulangi Manado. Jurnal EMBA ISSN 23031174 No.3. vol

Riahi \& Belkaoui. (2011). Accounting Theory (Teori Akuntansi). Buku 1. Edisi 5. Jakarta. Salemba Empat

Sujarweni. (2015). Akuntansi Sektor Publik. Yogyakarta. Pustaka Baru Press

Tinungki, Angelia.N.M., dan Pusung, J.Rudy. (2014). Penerapan Laporan Keuangan Organisasi Nirlaba Berdasarkan Psak No.45 Pada Panti Sosial Tresna Werdha Hana. Universitas Sam Ratulangi Manado. Jurnal EMBA ISSN 2303-1174. No.2. Vol 2. Diakses May, 16, 2018. Hal 809-819

Torang, Syamsir. (2013). Organisasi dan Manajemen (Perilaku, Sturktur, Budaya dan Perubahan Organisasi). Cetakan kesatu. Alfabeta. Bandung

Wibowo, Agus Purwaji, \& $\mathrm{H}$. Murtanto. (2016). Pengantar

Copyright (c) 2020 Mishelei Loen, SE., M.Si

This work is licensed under a Creative Commons Attribution-NonCommercial-ShareAlike 4.0 Internationa License. 
Akuntansi 1, Edisi 2. Jakarta.

Salemba Empat

Wonok, J.F. (2016). Penerapan Psak

No. 45 Tentang Pelaporan

Keuangan Entitas Nirlaba

Pada Jemaat Gmim Imanuel

Leilem. Universitas Sam

Ratulangi Manado, Jurnal

EMBA ISSN 2303-1174.

No.1. Vol 4.

Copyright (c) 2020 Mishelei Loen, SE., M.Si. 